\title{
THE RUMEN BACTERIAL COMMUNITY OF REINDEER IN DIFFERENT AGE PERIODS FROM RUSSIAN ARCTIC REGIONS
}

\author{
Larisa Ilina ${ }^{1}$, Valentina Filippova ${ }^{1}$, Andrey Dubrovin${ }^{1}$, Elena Yildirim¹, Timur Dunyashev ${ }^{1}$, Georgiy \\ Laptev $^{1}$, Kasim Laishev ${ }^{2}$ \\ ${ }^{1}$ BIOTROF+ LTD, Russia \\ ${ }^{2}$ North-West Center for Interdisciplinary Research on Food Security Problems, Russia \\ ilina@biotrof.ru
}

\begin{abstract}
Rangifer tarandus (reindeer) - is actively bred in the northern regions of different countries. Therefore, an urgent task is to deepen information about the features of reindeer adaptations. Rumen symbiotic microorganisms play an important role in the life of Rangifer tarandus, allowing animals to efficiently use scarce nutrient resources of the tundra and forest-tundra. The microbial community of the reindeer rumen, as well as its age-related changes, are the least studied compared to other ruminants. The comparative analysis results of rumen bacterial community composition of calf (4 months), young animals (1-2 years) and adults (3-6 years) Rangifer tarandus of the Russian Arctic are presented for the first time. The reindeer ruminal bacterial community composition was analyzed in the laboratory of the 'BIOTROF+' Ltd by T-RFLP method. In the ontogenesis, significant changes in the microorganism representation were noticed, the greatest of which was noted in microorganism involved in carbohydrate fermentation. The content of cellulolytic Clostridia and the acid-utilizing species of the Negativicutes $(\mathrm{P}<0.05)$ decreased with age, but bacteria with the amylo- and cellulosolytic properties of the phylum Bacteroidetes increased $(\mathrm{P}<0.05)$. A wide range of microorganisms which traditionally belong to the pathogens of various animals and humans diseases was revealed. With age, a tendency to increase the number of pathogens, including the bacteria of the families Campylobacteraceae, Burkholderiaceae, phylum Fusobacteria, and the genus Staphylococcus was noticed. The greatest percent of opportunistic microorganisms, including phylum Actinobacteria and the family Enterobacteriaceae, were detected in young animals.
\end{abstract}

Key words: reindeer, Rangifer tarandus, rumen bacterial community, T-RFLP-analysis, ontogeny, Russian Arctic regions.

\section{Introduction}

Providing the population of the Arctic regions with food is connected with reindeer (Rangifer tarandus) husbandry. The reindeer is a unique species of the animal, which as a result of expanding its habitat has acquired specific adaptations for life in the North. These are the only animals that can effectively use for nutrition meager plant resources of vast expanses of tundra, forest-tundra, northern taiga. So, for example, the share of lichen (Cladonia, Nephroma) carbohydrates assimilated by reindeer can reach $90 \%$ (Hungate, 1966).

Assimilation of plant fibers in reindeer, as in the rest of ruminant animals, is carried out by enzymes synthesized by rumen symbiotic microorganisms (Church, 2006). Among other representatives of the ruminant family Bovidae, the reindeer Rangifer tarandus are the least studied. The question of agerelated changes in the microbial community of the reindeer scar is barely illuminated, although it is of considerable interest in connection with the study of adaptations of their organism to the unfavorable conditions of habitat and nutrition.

The most informative for the study of rumen microbiota are methods aimed at studying the structure of the community as a whole, for example, NGS-sequencing and T-RFLP-analysis. These methods allow to detect and determine the content of low-level microorganisms in the rumen community, as demonstrated in the studies on cattle (Bos taurus taurus) (Jami \& Mizrahi, 2012; Veneman et al., 2015), sheep (Ovis aries) (de la Fuente et al., 2014; Snelling et al., 2014), deer (Rangifer tarandus tarandus) (Salgado-Flores et al., 2016), and goats (Capra aegagrus hircus) (Han et al., 2015; Wang et al., 2016).

Previously, using T-RFLP analysis, we conducted detailed studies of age-related changes in microbiota in cattle rumen, which demonstrated the development of the microbial community, coupled with the growth of calves and changes in their nutritional diet (Laptev et al., 2016).

According to modern ideas obtained on the basis of molecular genetic studies, it has been established that the total diversity of symbiotic microorganisms in the rumen of ruminant animals can reach several thousand species, including bacteria, fungi, archaea, protozoa, most of which are strictly anaerobic, uncultivated and unidentifiable species (Hungate, 1966; Tarakanov, 2002).

In this study, for the first time on the basis of molecular genetic analysis, we studied the age-related changes in the bacterial community of the reindeer rumen of the Russian Arctic. The aim of the study was to compare the taxonomic composition of bacteria present in the rumen of calves, young and adult Rangifer tarandus. 


\section{Materials and Methods}

The objects of the study were calves (4 months old), young animals (1-2 years old) and adults (3-6 years) of reindeer Rangifer tarandus of the Nenets breed. Samples of the contents of the rumen were selected in the summer-autumn period in 2017 from three animals from each age group in the Yamal-Nenets Autonomous Okrug (Harp, forest-tundra natural-climatic zone). On the average, the summer pasture ration of reindeer consisted of lichens (Cladonia, Nephroma) and plants (Betula nana, Betula pendula, Salix polaris, Salix borealis, Vaccinium uliginosum and others).

The composition of the bacterial community of the reindeer rumen was analyzed by T-RFLP (Terminal restriction fragment length polymorphism) (Laptev et al., 2016).

The total DNA from the samples was isolated using the Genomic DNA Purification Kit (Fermentas, Inc., Lithuania) according to the manufacturer's recommendations. PCR amplification was performed on a Verity DNA amplifier (Life Technologies, Inc., USA) using eubacterial primers 63F (CAGGCCTAACACATGCAAGTC) labeled at the 5' end WellRed D4 fluorophore (Beckman Coulter, USA) D4 WellRed ) and 1492R (TACGGHTACCTTGTTACGACTT), which allow the fragment of the $16 \mathrm{~S}$ rRNA gene to be amplified at positions 63 to 1492 at $95{ }^{\circ} \mathrm{C}$ for $3 \mathrm{~min}$ ( 1 cycle);

\section{Ratio of bacterial taxa in the content of reindeer rumen (Yamalo-Nenets Autonomous District)}

\begin{tabular}{|c|c|c|c|}
\hline \multirow{2}{*}{ Microorganisms } & \multicolumn{3}{|c|}{ Group of animals } \\
\hline & Calf (4 months) & Young (1-2 years) & Adults (3-6 years) \\
\hline Amount of phylotypes & $91.50 \pm 5.25$ & $109.50 \pm 4.15^{*}$ & $163.00 \pm 7.20^{* *}$ \\
\hline \multicolumn{4}{|l|}{ The proportion of the taxon, $\%$} \\
\hline Unclassified phylotypes & $12.38 \pm 0.57$ & $28.33 \pm 1.12^{*}$ & $13.77 \pm 0.95^{* *}$ \\
\hline Phylum Actinobacteria & $8.89 \pm 0.64$ & $12.20 \pm 0.52 *$ & $7.91 \pm 0.30 * *$ \\
\hline genus Bifidobacterium & $0.26 \pm 0.01$ & $1.09 \pm 0.06^{*}$ & $0.21 \pm 0.02 * *$ \\
\hline others & $8.63 \pm 0.35$ & $11.11 \pm 0.36^{*}$ & $7.70 \pm 0.21 * *$ \\
\hline Phylum Bacteroidetes & $10.12 \pm 0.42$ & $18.32 \pm 0.84^{*}$ & $13.45 \pm 0.64 * *$ \\
\hline Phylum Proteobacteria & $7.11 \pm 0.34$ & $4.34 \pm 0.21 *$ & $13.49 \pm 0.34 * *$ \\
\hline family Enterobacteriaceae & $0.31 \pm 0.02$ & $1.83 \pm 0.09^{*}$ & $1.00 \pm 0.04 * *$ \\
\hline family Campylobacteriaceae & $5.99 \pm 0.36$ & $1.30 \pm 0.05^{*}$ & $9.69 \pm 0.35^{* *}$ \\
\hline family Pseudomonadaceae & $0.71 \pm 0.05$ & $0.32 \pm 0.05^{*}$ & $0.48 \pm 0.02$ \\
\hline family Burkholderiaceae & $0.11 \pm 0.02$ & $0.89 \pm 0.04 *$ & $2.32 \pm 0.08^{* *}$ \\
\hline Phylum Fusobacteria & $0.78 \pm 0.25$ & $0.18 \pm 0.01^{*}$ & $1.65 \pm 0.05^{* *}$ \\
\hline Phylum Cyanobacteria & - & $0.70 \pm 0.03$ & $0.75 \pm 0.02$ \\
\hline Phylum Acidobacteria & - & - & $0.33 \pm 0.01$ \\
\hline Phylum Firmicutes & $60.74 \pm 2.14$ & $35.93 \pm 1.63 *$ & $48.65 \pm 1.96^{* *}$ \\
\hline class Clostridia & $39.03 \pm 1.98$ & $15.12 \pm 0.65^{*}$ & $26.86 \pm 1.21^{* *}$ \\
\hline family Thermoanaerobacteraceae & $0.16 \pm 0.02$ & $0.24 \pm 0.01$ & $0.12 \pm 0.01$ \\
\hline family Lachnospiraceae & $6.12 \pm 0.22$ & $2.30 \pm 0.10^{*}$ & $2.72 \pm 0.35$ \\
\hline family Eubacteriaceae & $21.04 \pm 1.02$ & $9.47 \pm 0.34 *$ & $15.34 \pm 0.48^{* *}$ \\
\hline family Ruminococcaceae & $-* * *$ & $0.19 \pm 0.01$ & - \\
\hline family Clostridiaceae & $11.61 \pm 0.25$ & $2.61 \pm 0.20^{*}$ & $8.36 \pm 0.38 * *$ \\
\hline genus Peptococcus & $0.11 \pm 0.02$ & $0.31 \pm 0.02 *$ & $0.32 \pm 0.01$ \\
\hline genus Lactobacillus & $0.40 \pm 0.12$ & $2.66 \pm 0.12 *$ & $1.12 \pm 0.06^{* *}$ \\
\hline genus Bacillus & $2.39 \pm 0.19$ & $4.37 \pm 0.25^{*}$ & $5.03 \pm 0.22$ \\
\hline genus Staphylococcus & - & $0.10 \pm 0.01$ & $0.31 \pm 0.02 * *$ \\
\hline class Negativicutes & $18.92 \pm 2.20$ & $13.68 \pm 0.54 *$ & $15.33 \pm 0.63$ \\
\hline
\end{tabular}

$* \mathrm{P}<0.05$ - differences between age groups, calves / young.

$* * \mathrm{P}<0.05$ - differences between age groups, young / adult.

*** - below the limit of reliable determination by the T-RFLP method. 
$95{ }^{\circ} \mathrm{C}-30 \mathrm{~s}, 55^{\circ} \mathrm{C}-40 \mathrm{~s}, 72{ }^{\circ} \mathrm{C}-60 \mathrm{~s}(35$ cycles $)$, $72{ }^{\circ} \mathrm{C}-5 \mathrm{~min}$.

The concentration of total DNA in the solution was determined using a Qubit fluorometer (Invitrogen, Inc., USA) using 'Qubit dsDNA BR Assay Kit' (Invitrogen, Inc., USA), as recommended by the manufacturer.

The fluorescently labeled amplicones of the $16 \mathrm{~S}$ rRNA gene were purified by a standard procedure (Maniatis et al., 1984). The restriction of $30-50$ ng DNA was carried out with restriction enzymes HaeIII, HhaI and MspI following the manufacturer's recommendation (Fermentas, Lithuania) for 2 hours at $37{ }^{\circ} \mathrm{C}$. The restriction products were precipitated with ethanol, then $0.2 \mu \mathrm{L}$ of the Size Standard-600 molecular weight marker (Beckman Coulter, USA) and $10 \mu \mathrm{L}$ of Sample Loading Solution formamide (Beckman Coulter, USA) were added. The analysis was carried out using CEQ 8000 (Beckman Coulter, USA) according to the manufacturer's recommendations. The error of the CEQ 8000 device was not more than $5 \%$. The calculation of peak sizes and areas was carried out in the Fragment Analysis program (Beckman Coulter, USA), on the basis of which subtypes (filotypes) were distinguished with a 1-nucleotide error in the study and their relative content in the microbial community was determined.

The affiliation of bacteria to a specific taxonomic group was determined using the database (http://mica. ibest.uidaho.edu/trflp.php).

Statistical processing of the results was carried out using the analysis of variance using Microsoft Excel 2010 software.

\section{Results and Discussion}

For the first time we characterized the age-related changes in the composition of the rumen bacterial community for the Russian Arctic Rangifer tarandus using the molecular genetic method of T-RFLP. Analyses were made for calves of 4 months of age, young animals (1-2 years old) and adults (3-6 years). The first years of life are the most critical for reindeer. During this period the highest percentage of death is observed, which is probably due to the scarcity of the diet in the conditions of natural habitats (Samandas, Laishev, \& Samoylov, 2011).

In the process of ontogenesis in Rangifer tarandus, the development of the bacterial community, the appearance of new taxa of microorganisms was observed (Table 1). The spectrum of bacteria detected in young animals and adults was more widespread than in 4-month-old calves - over 109.50 $\pm 4.15(\mathrm{P}<0.05)$. Most of the bacterial phylotypes, as a result of the assessment of taxonomic affiliation, were assigned to the Firmicutes, the total percentage of which was observed in 4-month-old calves $(\mathrm{P}<0.05)$. The bacteria of the phylums Bacteroidetes, Actinobacteria and Proteobacteria were found in the Rangifer tarandus rumen community in a lesser extent. In a minor amount representatives of phylums Tenericutes and Fusobacteria, Acidobacteria, Cyanobacteria were identified.

The part of philotypes that could not be identified by databases was also significant. The largest proportion of unidentified taxa was observed in individuals 1-2 years old. The results are compatible with the results of researchers who reported the presence of a higher number of unidentified taxa in the rumen of the Rangifer tarandus tarandus of Norway, compared with cattle and Thompson's gazelles (Sundset et al., 2007). This indicates the need for a set of additional studies to establish the role of these microorganisms in the livelihoods of reindeer.

Therefore, in general, using T-RFLP-analysis, we obtained results comparable to modern ideas about the microbiota of rumen of ruminant animals (Hungate, 1966; Tarakanov, 2002; Church, 2006).

It is worth noting some differences in the composition of the bacterial community, found in the studied specimens of reindeer, from other ruminants. Rangifer tarandus almost completely lacked the cellulolytic bacteria of the family Ruminococcaceae traditionally detected in the rumen of cattle in significant quantities. In this case, the percentage of bacteria of the Eubacteriaceae family of Clostridia class with cellulose and saccharolytic properties was, on the contrary, higher than reported for cattle (Hungate, 1966). According to some authors, the unique ability of eubacteria, in particular Eubacterium rangiferina, is the ability to detoxify secondary lichen metabolites that are toxic to other ruminants (Sundset et al., 2008). The presence of Cyanobacteria - photosynthesizing microorganisms, which are cyanobionts of lichens, is also a point of interest in the microbiota of the reindeer rumen.

A comparative analysis of Rangifer tarandus rumen microbiota showed the presence of certain patterns in the development of the bacterial community associated with the age of the animals.

One of the indicators characterizing the microflora of the 'adult type' in ruminants is its ability to digest fiber (Nocek, 1997). The studies of rumen microbiota using T-RFLP-analysis showed that reindeer already at 4 months of age are able to digest significant amounts of fiber. It is based on the relative amount of bacteria involved in the fermentation of carbohydrates of plant feed. At the same time, with age, the proportion of these microorganisms in the rumen of animals did not increase significantly.

In contrast, in the process of ontogenesis in reindeer, there was a significant decrease in the total content of Clostridia $(\mathrm{P}<0.05)$, which potentially 
have the ability to ferment polysaccharides of plants with the formation of VFA (volatile fatty acids). In 4-month-old calves, the percentage of bacteria of the Clostridiaceae family was significantly higher $(\mathrm{P}<0.05)$. The young reindeers have a tendency to decrease the level of representatives of the Clostridia, including the Eubacteriaceae and Clostridiaceae. The relative abundance of these microorganisms in 4-month-old calves and adults was significantly higher $(\mathrm{P}<0.05)$. The content of other microorganisms that have the ability to ferment starch, fiber, a number of other carbohydrates, proteins, and also deaminate amino acids from the phylum Bacteroidetes (including the genera Bacteroides, Prevotella) significantly increased $(\mathrm{P}<0.05)$ with the age of the animals.

Characterization of identified age-related changes requires clarification and additional studies, because the trends can be related to both the physiological characteristics of this stage of development of animals, and with other factors.

Representation in the rumen of the studied animals the microorganisms of the Negativicutes class, capable of utilizing the mono-, oligo-, polysaccharides, acids formed during fermentation, was high and tended to decrease in ontogeny $(\mathrm{P}<0.05)$. The reindeer have a reverse pattern between the content of bacteria of the Negativicutes class and microorganisms of the genus Lactobacillus (the main metabolite of which is lactate) which confirms the importance of acid-utilizing bacteria for ruminant animals.

The variety of pathogenic and opportunistic bacteria in the reindeer rumen is practically not described in the literature. The most studied in this regard are the causative agents of necrobacteriosisFusobacterium necrophorum. Necrobacteriosis in winter often causes the mass death of young animals. Thus, it is shown that in cattle Fusobacteria are able to penetrate into the blood, infecting the animal organism with the development of liver abscesses, hoof lesions, skin, and mucous membranes (Samandas, Laishev, \& Samoylov, 2011; Laptev et al., 2016).

Based on the results of the T-RFLP analysis, in the rumen of the investigated reindeer the presence of a wide range of microorganisms was found, which traditionally belong to the causative agents of various animal and human diseases. The highest in Rangifer tarandus was the abundance of phylum Actinobacteria and families of Campylobacteriaceae and Enterobacteriaceae. To a lesser extent the representatives of the families Pseudomonadaceae, Burkholderiaceae, genus Staphylococcus were identified in the reindeer rumen. At the same time there is a tendency to increase the representation of a number of the pathogenic and opportunistic bacteria in the rumen of animals during ontogeny.

\section{Conclusions}

The results of the conducted studies indicate the presence of significant age-related changes in Rangifer tarandus rumen microbiota. As part of the bacterial community of the reindeer rumen, a number of differences from other ruminants have been identified, which may be explained by the physiological characteristics of these unique animals and their adaptability to conditions in the Arctic regions. In general, the obtained results indicate an expansion of the taxonomic diversity of microorganisms during ontogenesis, accompanied by the gradual settlement of the rumen with new microorganisms.

\section{Acknowledgements}

The research was carried out with the support of the grant of the Russian Science Foundation (RSCF) № 17-76-20026 'Microbiocenosis of the Rangifer tarandus rumen of the Arctic regions of Russia as a fundamental basis for obtaining promising biotechnologies for farm animals'.

\section{References}

1. Church, D.C. (1993). Ruminant Animal: Digestive phisiology and nutrition. New Jersey: Prentice Hall.

2. de la Fuente, G., Belanche, A., Girwood, S.E., Pinloche, E., Wilkinson, T., \& Newbold, C.J. (2014). Pros and Cons of Ion-Torrent next generation sequencing versus Terminal Restriction Fragment Length Polymorphism T-RFLP for studying the rumen bacterial community. PLoS ONE. 9(7), e101435. DOI: 10.1371/journal.pone.01014 35.

3. Han, X., Yang, Y., Yan, H., Wang, X., Qu, L., \& Chen, Y. (2015). Rumen Bacterial Diversity of 80 to 110-day-old goats using 16S rRNA sequencing. PLoS ONE. 10(2), e0117811. DOI: 10.1371/journal. pone.0117811.

4. Hungate, R.E. (1966). The Rumen and its Microbes. New York: Academic Press.

5. Jami, E., \& Mizrahi, I. (2012). Composition and similarity of bovine rumen microbiota across individual animals. PLoS ONE. 7 (3), e33306. DOI: 10.1371/journal.pone.0033306.

6. Laptev, G.Yu., Novikova, N.I., Ilina, L.A., Yildirim, E.A., Nagornova, K.V., Dumova, V.A., Soldatova, V.V., Bolshakov, V.N., Gorfunkel, E.P., Dubrovina, E.G., Sokolova, O.N., Nikonov, I.N., \& Lebedev, A.A. (2016). Norms for the maintenance of microflora in rumen of cattle. Saint-Petersburg: BIOTROF.

7. Maniatis, T., Fritsch, E., \& Sembrook, J. (1984). Molecular cloning. Moscow: Mir. 
8. Nocek, J.E. (1997). Bovine acidosis: implications on laminitis. J. Dairy Sci. 80, 1005-1028. DOI: 10.3168/ jds.S0022-0302(97)76026-0.

9. Salgado-Flores, A., Hagen, L.H., Ishaq, S.L., Zamanzadeh, M., Wright, A-D.G., \& Pope, P.B. (2016). Rumen and cecum microbiomes in Reindeer (Rangifer tarandus tarandus) are changed in response to a lichen diet and may affect enteric methane emissions. PLOS ONE. 11(5), e0155213. DOI: 10.1371/journal. pone. 0155213.

10. Samandas, A.M., Laishev, K.A., \& Samoylov, S.G. (2011). Modern epizootic situation of necrobacteriosis of reindeers in Taimyr. Siberian Herald of Agricultural Science, 5-6, 92-96.

11. Snelling, T.J., Genç, B., McKain, N., Watson, M., Waters, S.M., \& Creevey, C.J. (2014). Diversity and community composition of methanogenic archaea in the rumen of scottish upland sheep estimates by different methods. PLoS ONE. 9 (9), e106491. DOI: 10.1371/journal.pone.0106491.

12. Sundset, M.A., Præsteng, K.E., Cann, I.K., Mathiesen, S.D., \& Mackie, R.I. (2007). Novel rumen, bacterial diversity in the two geographically separated sub-species of reindeer. Microbial. Ecology. 54, 424-438. DOI: 10.1007/s00248-007-9254-x.

13. Sundset, M.A., Kohn, A., Mathiesen, S.D., \& Presteng, K.E. (2008). Eubacterium rangiferina, a novel usnic acid-resistant bacterium from the reindeer rumen. Naturwissenschaften. 95, 741-749. DOI: 10.1007/ s00114-008-0381-0.

14. Tarakanov, B.V. (2006). Methods of studying the microflora of the digestive tract of agricultural animals and poultry. Moscow: Science world.

15. Veneman, J.B., Muetzel, S., Hart, K.J., Faulkner, C.L., Moorby, J.M., \& Perdok, H.B. (2015). Does dietary mitigation of enteric methane effect affect rumen function and animal productivity in dairy cows? PLoS ONE. 10(10), e0140282. DOI: 10.1371/journal.pone.0140282.

16. Wang, L., Xu, Q., Kong, F., Yang, Y., Wu, D., \& Mishra, S. (2016). Exploring the goat rumen microbiome from seven days to two years. PLoS ONE. 11(5), e0154354. DOI: 10.1371/journal.pone.0154354. 